\title{
Research Article \\ Effect of Rare Earth Metals, Sr, and Ti Addition on the Microstructural Characterization of A413.1 Alloy
}

\author{
M. G. Mahmoud, ${ }^{1}$ A. M. Samuel, ${ }^{1}$ H. W. Doty, ${ }^{2}$ S. Valtierra, ${ }^{3}$ and F. H. Samuel ${ }^{1}$ \\ ${ }^{1}$ Université du Québec à Chicoutimi, Chicoutimi, QC, Canada \\ ${ }^{2}$ General Motors, Materials Engineering, 823 Joslyn Avenue, Pontiac, MI 48340, USA \\ ${ }^{3}$ Nemak, S.A., Libramiento Arco Vial Km. 3.8, 66000 Garcia, NL, Mexico \\ Correspondence should be addressed to F. H. Samuel; fhsamuel@uqac.ca
}

Received 5 February 2017; Accepted 9 March 2017; Published 16 May 2017

Academic Editor: Patrice Berthod

Copyright (C) 2017 M. G. Mahmoud et al. This is an open access article distributed under the Creative Commons Attribution License, which permits unrestricted use, distribution, and reproduction in any medium, provided the original work is properly cited.

\begin{abstract}
The present work was performed on A413.1 alloy containing 0.2-1.5 wt\% rare earth metals (lanthanum or cerium), $0.05-0.15 \% \mathrm{Ti}$, and $0-0.02 \mathrm{wt} \% \mathrm{Sr}$. These elements were either added individually or combined. Thermal analysis, image analysis, and electron probe microanalysis were the main techniques employed in the present study. The results show that the use of the depression in the eutectic temperature as a function of alloy modification cannot be applied in the case when the alloy is treated with rare earth metals. Increasing the concentration of RE increases the solidification zone especially in Sr-modified alloys leading to poor feeding ability. This observation is more prominent in the case of Ce addition. Depending upon the amount of added Ti, two RE based intermetallics can be formed: (i) a white phase, mainly platelet-like (approximately $2.5 \mu \mathrm{m}$ thick), that is rich in $\mathrm{RE}, \mathrm{Si}, \mathrm{Cu}$, and $\mathrm{Al}$ and (ii) a second phase made up of mainly grey sludge particles (star-like) branching in different directions. The grey phase is rich in Ti with some RE (almost $20 \%$ of that in the white phase) with traces of Si and Cu. There is a strong interaction between RE and $\mathrm{Sr}$ leading to a reduction in the efficiency of $\mathrm{Sr}$ as a eutectic Si modifier causing particle demodification.
\end{abstract}

\section{Introduction}

Rare earth elements such as $\mathrm{La}, \mathrm{Ce}, \mathrm{Nd}, \mathrm{Y}$, and mischmetal are reported to be capable of modifying the eutectic structure in Al-Si alloys. Modification with RE elements was explained by Sharan and Saksena [1] using the critical growth temperature hypothesis, in which the modifying element should exhibit a tendency to form compounds with the precipitating phase (Si) at a temperature below the normal eutectic temperature, and should also exhibit little compound-forming tendency with the solvent phase $(\alpha-\mathrm{Al})$. Lanthanum (La) meets these requirements, but $\mathrm{Ce}$ and $\mathrm{Nd}$ satisfy them only partially. In addition, RE elements satisfy the minimum criteria such as atomic radius, melting point, vapor pressure, and free energies of oxide formation, thus exhibiting the capability to modify the eutectic Si. Rare earth elements have been added to Al-Si alloys in the form of mischmetal (MM), a mixture of rare earths found in nature, and also in the form of specific rare earth metals and fluorides.
The main role of rare earth (RE) metals as modifiers is to change the mode of growth of the eutectic silicon. Lanthanum is the most powerful of its kind. Microadditions of RE should be enough to modify the eutectic Si particles provided that a critical cooling rate is reached. RE-treated alloys can maintain the modified structure much longer than Na-treated alloys. A reliable and persistent eutectic modification effect can be obtained with rare earth addition [2-6]. However, the minimum amount of rare earths necessary to obtain proper modification is exceptionally large. Ye et al. [6] showed that both as-cast grain size and secondary dendrite arm spacing were decreased by adding cerium (Ce) and lanthanum (La) metals. They also reported that the intermetallic compound $\mathrm{Fe}_{2} \mathrm{SiAl}_{8}$ was replaced with four main rare earth compounds, $\mathrm{Ce}_{5} \mathrm{Si}_{3}, \mathrm{La}_{5} \mathrm{Si}_{3}, \mathrm{Al}_{10} \mathrm{Fe}_{2} \mathrm{Ce}$, and $\mathrm{Al}_{10} \mathrm{Fe}_{2} \mathrm{La}$, with the addition of the two RE metals.

It has been observed that, with increasing mischmetal addition, coarse silicon plates in A356 alloy convert first into fine plates and then finally into globular particles at about 
1.0\% MM addition. Small additions do not seem to be effective, and depression to the temperature of globular growth is possible only with about $1.0 \%$ addition. Rare earth elements also have a modification effect on the $\alpha$-Al in the microstructure. By comparing the as-cast microstructure of the alloy containing 1 pct MM, with that of the unmodified alloy, it is evident that MM addition reduces the secondary dendrite arm spacing (DAS) [7-10].

As the rare earth addition level approaches $2 \%$, some primary dendrite refinement (reduction in secondary dendrite arm spacing) becomes apparent $[6,11,12]$. This is attributed to an alloying effect and is not significant enough to be considered as a practical means of reducing secondary dendrite arm spacing. The silicon phase modified by rare earth exhibits the same changes in crystallographic structure as achieved through modification with sodium. In both cases, the silicon phase changes from growth in the $\langle 211\rangle$ directions to growth in the $\langle 100\rangle$ directions, where it develops a refined, rounded, and interconnected morphology. Ye et al. [6] report that, during solidification, the eutectic undercooling increases up to $15 \mathrm{~K}$ at 1 pct $\mathrm{MM}$ addition and up to $25 \mathrm{~K}$ at 2 pct addition. This enables more nuclei to form and result in a finer structure (DAS as well as eutectic silicon). However, their investigations indicate that the addition of MM beyond 1 pct does not reduce the DAS; instead, it increases it to the same level as in the base alloy.

Cerium $[13,14]$ is reported to have only $0.05 \mathrm{wt}$ pct solid solubility in aluminum, while La does not have measurable solid solubility. Only a very small fraction of the Ce and La contents of mischmetal goes into solution. A greater part concentrates ahead of the interface during solidification to produce constitutional supercooling, and, hence, the dendrite structure of the alloy is refined [6]. The eutectic undercooling in the same alloy is increased by as much as $25 \mathrm{~K}$, with an increase in MM addition up to 2 pct, and complete modification is obtained. Sharan and Saksena [14] have also shown that the separate addition of $0.75 \% \mathrm{Ce}$ and $0.05 \%$ La leads to partial modification of the microstructure, while complete modification is produced with the addition of $0.2 \%$ lanthanum fluorides.

The present study is part of an ongoing long-term research program initiated by the present authors in order to establish the interactions between the rare earth metals and both $\mathrm{Sr}$ and $\mathrm{Ti}$ and how these interactions would control the microstructure constituents of the A413.0 alloy solidified at a near equilibrium rate.

\section{Experimental Procedure}

The A413.0 casting alloy used in this study was supplied in the form of $12.5 \mathrm{~kg}$ ingots. The chemical composition of the base alloy used for this research is listed in Table 1. In order to obtain the cooling curves and to identify the main reactions and corresponding temperatures occurring during the solidification of A413.1 alloys, thermal analysis of all alloy melts prepared was carried out. Ingots of the as-received commercial A413.1 alloy were cut into smaller pieces, cleaned, and then dried to prepare the required alloy compositions.
TABLE 1: Chemical composition of the as received A413.1 alloy.

\begin{tabular}{lccccccc}
\hline Element & $\mathrm{Si}$ & $\mathrm{Cu}$ & $\mathrm{Fe}$ & $\mathrm{Mg}$ & $\mathrm{Mn}$ & $\mathrm{Ti}$ & $\mathrm{Zn}$ \\
\hline Wt.\% & 11.4 & 0.16 & 0.23 & 0.18 & 0.14 & 0.05 & 1.1 \\
\hline
\end{tabular}

The melting process was carried out in a cylindrical graphite crucible of $2 \mathrm{~kg}$ capacity, using an electrical resistance furnace; the melting temperature was maintained at $750^{\circ} \mathrm{C}$ while alloying elements were added, as shown in Table 2 . Rare earth metals were added in the form of $\mathrm{Al}-15 \mathrm{wt} \% \mathrm{RE}$, whereas $\mathrm{Ti}$ and $\mathrm{Sr}$ were added in the form $\mathrm{Al}-5 \mathrm{wt} \% \mathrm{Ti}-1 \mathrm{wt} \% \mathrm{~B}$ and $\mathrm{Al}-$ $10 \mathrm{wt} \%$ Sr master alloys, respectively.

A high sensitivity type-K (chromel-alumel) thermocouple, which has to be insulated using a double-holed ceramic tube, is attached to the centre of the graphite mold. The temperature-time data is collected using a high-speed data acquisition system linked to a computer system to record the temperature-time data every 0.1 seconds. Figure 1 shows a schematic representation of the graphite mold (heated at $600^{\circ} \mathrm{C}$ ) and thermal analysis set-up. From this data, the solidification curves and the corresponding first derivative curves for a number of selected alloys were plotted so as to identify the main reactions occurring during solidification with the corresponding temperatures.

The microstructures were examined by means of a Leica DM LM optical microscope. The grain-size measurements were carried out using a Clemex image analyzer in conjunction with the optical microscope. The grain size was obtained from the average of 200 measurements taken over 20 fields (10 measurements per field) at 100x magnification for each alloy sample. Phase identification was carried out using an electron probe microanalyzer (EPMA) in conjunction with energy dispersive X-ray analysis (EDX) and wavelength dispersive spectroscopic analysis (WDS) where required, integrating a combined JEOL JXA-89001 WD/ED microanalyzer operating at $20 \mathrm{KV}$ and $30 \mathrm{nA}$, where the size of the spot examined was $\sim 2 \mu \mathrm{m}$.

\section{Results and Discussion}

3.1. Solidification Curves. Solidification kinetics of an unmodified and Sr-modified near-eutectic Al-Si alloy were analyzed by Aparicio et al. [16] who found that there are changes in the solidification rate during eutectic nucleation followed by similar solidification rate evolutions during growth, suggesting that this parameter is governed principally by the heat extraction conditions. The work of Hengcheng et al. [17] on the effects of $\mathrm{Sr}$ and solidification rate on eutectic grain structure in an $\mathrm{Al}-13 \mathrm{wt} \% \mathrm{Si}$ alloy revealed that the characteristic temperature of eutectic nucleation $\left(T_{N}\right)$, the minimum temperature prior to recalescence $\left(T_{M}\right)$, and the growth temperature $\left(T_{\mathrm{G}}\right)$ during cooling as determined by quantitative thermal analysis are continuously decreased with increasing Sr content. As mentioned previously, Nogita et al. [18] reported that all rare earth elements had some effect on the eutectic silicon; however, europium was the only element to cause fully modified, fine fibrous silicon, whereas the other 
TABLE 2: Chemical composition and codes of the A413.1 alloys used in the present study, graphite mold castings.

\begin{tabular}{|c|c|c|c|c|c|c|c|c|c|}
\hline \multirow{3}{*}{ Alloy } & \multirow{3}{*}{ Mold type } & \multirow{3}{*}{ Mold temp $\left({ }^{\circ} \mathrm{C}\right)$} & \multirow{3}{*}{ Alloy code } & \multicolumn{6}{|c|}{ Additives (wt $\%)^{*}$} \\
\hline & & & & \multicolumn{3}{|c|}{ Aimed } & \multicolumn{3}{|c|}{ Actual } \\
\hline & & & & $\mathrm{Sr}$ & $\mathrm{La}$ & $\mathrm{Ce}$ & $\mathrm{Sr}$ & $\mathrm{La}$ & $\mathrm{Ce}$ \\
\hline \multirow{24}{*}{ A 413.1} & \multirow{24}{*}{ Graphite } & \multirow{24}{*}{600} & $\mathrm{TE}$ & 0 & 0 & 0 & 0 & 0 & 0 \\
\hline & & & TE10 & 0 & 0.2 & 0 & 0 & 0.187 & 0 \\
\hline & & & TE1 & 0 & 0.5 & 0 & 0 & 0.284 & 0 \\
\hline & & & TE2 & 0 & 1 & 0 & 0 & 0.717 & 0 \\
\hline & & & TE3 & 0 & 1.5 & 0 & 0 & 0.940 & 0 \\
\hline & & & TE11 & 0 & 0 & 0.2 & 0 & 0.022 & 0.083 \\
\hline & & & TE4 & 0 & 0 & 0.5 & 0 & 0.237 & 0.308 \\
\hline & & & TE5 & 0 & 0 & 1 & 0 & 0.067 & 0.300 \\
\hline & & & TE6 & 0 & 0 & 1.5 & 0 & 0.078 & 0.634 \\
\hline & & & TE7 & 0 & 0.5 & 0.5 & 0 & 0.321 & 0.163 \\
\hline & & & TE8 & 0 & 1 & 1 & 0 & 0.511 & 0.387 \\
\hline & & & TE9 & 0 & 1.5 & 1.5 & 0 & 0.840 & 0.497 \\
\hline & & & TES & 0.1 & 0 & 0 & 0.0088 & 0 & 0 \\
\hline & & & TE10S & 0.01 & 0.2 & 0 & 0.0078 & 0.187 & 0 \\
\hline & & & TE1S & 0.01 & 0.5 & 0 & 0.0087 & 0.284 & 0 \\
\hline & & & TE2S & 0.01 & 1 & 0 & 0.0065 & 0.717 & 0 \\
\hline & & & TE3S & 0.01 & 1.5 & 0 & 0.0079 & 0.940 & 0 \\
\hline & & & TE11S & 0.01 & 0 & 0.2 & 0.0193 & 0.022 & 0.083 \\
\hline & & & TE4S & 0.01 & 0 & 0.5 & 0.0123 & 0.237 & 0.308 \\
\hline & & & TE5S & 0.01 & 0 & 1 & 0.0081 & 0.067 & 0.300 \\
\hline & & & TE6S & 0.01 & 0 & 1.5 & 0.008 & 0.078 & 0.634 \\
\hline & & & TE7S & 0.01 & 0.5 & 0.5 & 0.0079 & 0.321 & 0.163 \\
\hline & & & TE8S & 0.01 & 1 & 1 & 0.0084 & 0.511 & 0.387 \\
\hline & & & TE9S & 0.01 & 1.5 & 1.5 & 0.0081 & 0.840 & 0.497 \\
\hline
\end{tabular}

${ }^{*} \mathrm{Ti}$ in the amount of $0.15 \mathrm{wt} \%$ was added to selected alloys.

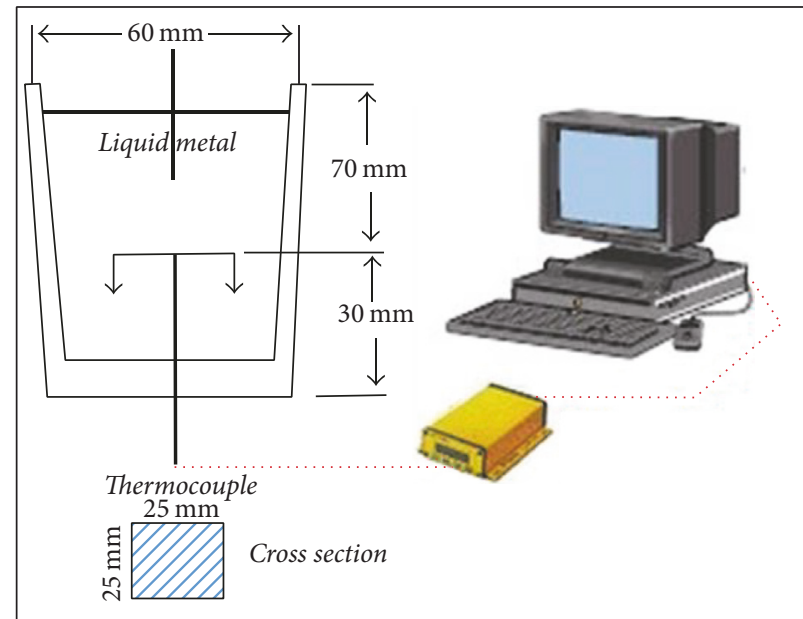

FIGURE 1: Schematic drawing showing the graphite mold used for thermal analysis.

elements only produced a minor refinement of the plate-like silicon morphology.

Ferdian et al. [15]. studied the effect of cooling rate on the eutectic modification in 356 alloy. Figure 2 shows the parameters taken from thermal analysis cooling curves for characterizing the (Al)-Si eutectic arrest according to the authors: minimum eutectic temperature $\left(T_{\mathrm{e}, \mathrm{min}}\right)$, maximum eutectic temperature $\left(T_{\mathrm{e}, \max }\right)$, and recalescence $\left(\Delta T_{\mathrm{e}}\right)$. In the case of no recalescence, $T_{e, \max }$ was obtained as the temperature for which the absolute value of the cooling rate 


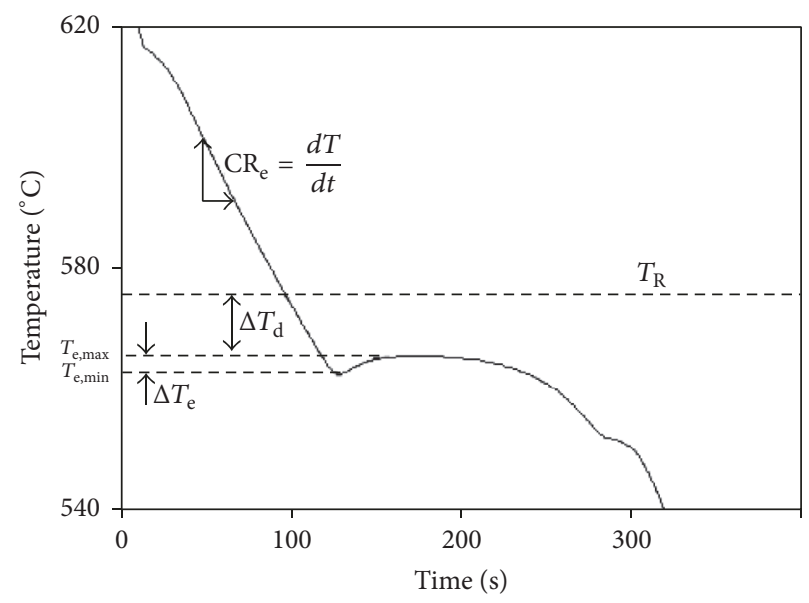

FIGURE 2: Solidification parameters of 356 alloy [15].

(time derivative of the cooling curve) was highest. $\Delta T_{\mathrm{d}}=T_{\mathrm{R}}-$ $T_{\text {e,max }}$ is the eutectic depression, where $T_{\mathrm{R}}$ is the equilibrium eutectic temperature calculated using an equation obtained by updating the one proposed by Mondolfo [19]:

$$
\begin{gathered}
T_{\mathrm{R}}\left({ }^{\circ} \mathrm{C}\right)=577-\frac{12.5}{w_{\mathrm{Si}}} \cdot\left(4.59 \cdot w_{\mathrm{Mg}}+1.37 \cdot w_{\mathrm{Fe}}+1.65\right. \\
\left.\cdot w_{\mathrm{Cu}}+0.35 \cdot w_{\mathrm{Zn}}+2.54 \cdot w_{\mathrm{Mn}}+3.52 \cdot w_{\mathrm{Ni}}\right) .
\end{gathered}
$$

Applying this equation for the present alloy shows that $T_{\mathrm{R}}$ for A413.1 is about $574^{\circ} \mathrm{C}$.

Figures 3-5 demonstrate the thermal parameters of the 11 alloys used in the present work without (Figure 3(a)) and with $80 \mathrm{ppm} \mathrm{Sr}$ (Figure 3(b)). In the absence of Sr, the minimum depression in eutectic temperature is about $1^{\circ} \mathrm{C}$ and maximum $(1.5 \% \mathrm{La}+1.5 \% \mathrm{Ce})$ is about $3^{\circ} \mathrm{C}$. The addition of $1.5 \mathrm{wt} \% \mathrm{RE}$ resulted in increasing the alloy solidification point by about $12^{\circ} \mathrm{C}$. The increase in the melting temperature is mainly due to the presence of $\mathrm{Ce}$. The observed increase in melting point is independent of the addition of Sr (Figure 4(a)). Considering the change in the eutectic temperature, modification with 80 ppm Sr (Figure 3(b)) caused depression in the eutectic temperature by about $7^{\circ} \mathrm{C}$. Addition of La or $\mathrm{Ce}$ up to $1.5 \mathrm{wt} \%$ is associated with fluctuation in the depression in the eutectic temperature by about $\pm 1.5^{\circ} \mathrm{C}$ (Figure 4 ) to that obtained from the base alloy with $80 \mathrm{ppm} \mathrm{Sr}$ (Figure 5). Thus, it is difficult to use the well-established concept of the depression in the eutectic temperature [20] when the alloy is treated with RE. It is interesting to note that, with addition of about $3 \mathrm{wt} \% \mathrm{RE}$, the eutectic temperature rose by about $4^{\circ} \mathrm{C}$ which may be due to RE-Sr interaction.

\subsection{Microstructural Evolution}

3.2.1. Grain Refining and Intermetallic Phases. In $\mathrm{Al}-5 \% \mathrm{Ti}-$ $1 \% \mathrm{~B}$ master alloy with $\mathrm{Ti} / \mathrm{B}>2.22$, Ti in excess of $\mathrm{TiB}_{2}$ stoichiometry goes into solution and is expected to behave in a similar fashion to that of Al-Ti master alloys. Although the nominal Ti addition levels for the Al-5Ti-1B and Al-10Ti grain refiners would be the same in a melt, they represent different $\mathrm{Ti}$ solute levels. All of the $\mathrm{Ti}$ from Al-10Ti forms solute (after the $\mathrm{Al}_{3} \mathrm{Ti}$ intermetallic particles dissolve), whereas only about $56 \%$ of the $\mathrm{Ti}$ from the Al-5Ti-1B forms solute, the remainder being tied up in the $\mathrm{TiB}_{2}$ particles [21]. From the observation of preferential precipitation of $\mathrm{Ti}\left(\mathrm{Al}_{1-x}, \mathrm{Si}_{x}\right)_{3}$ on $\mathrm{TiB}_{2}$, it appears that both $\mathrm{Ti}$ and $\mathrm{Si}$ have an affinity to segregate onto the $\mathrm{TiB}_{2}$ surface [22].

Easton and StJohn [23] proposed that the optimum chemical grain refiner needs to include both solute titanium (with its very high growth restriction factor, GRF) and nucleant particles (e.g., $\mathrm{TiB}_{2}$ or $\mathrm{TiAl}_{3}$ ) in order to produce effective grain refinement. For this reason, the Al-5Ti-lB type of refiner is extremely effective. The GRF of any solute element is given by the factor, $m C_{o}(k-1)$, where $m$ is the gradient of the liquidus line in the binary alloy phase diagram, $C_{o}$ is the concentration of the solute in the alloy, and $k$ is the partition coefficient.

Figure 6 is the microstructure of the base alloy modified with $80 \mathrm{ppm}$ Sr. The secondary dendrite arm spacing is about $87 \mu \mathrm{m}$; note the presence of $\alpha-\mathrm{Al}_{15}(\mathrm{Mn}, \mathrm{Fe})_{3} \mathrm{Si}_{2}$ within the $\alpha$ $\mathrm{Al}$. The effect of the addition of grain refiner on the grain size and distribution is shown in Figure 7. It is clear that the use of grain refiner in the amount of $0.15 \mathrm{wt} \%$ Ti resulted in wellrefined grains with homogeneous distribution throughout the matrix.

Figures 8 and 9 are backscattered electron images of Laand Ce-containing alloys, respectively. Two main observations can be made:

(i) For a given Ti content, it is difficult to distinguish between La- and Ce-containing phases since both elements produce similar morphologies (atomic weights of La and Ce are 58 and 59, resp.).

(ii) Increasing the amount of added Ti resulted in the formation of a large volume fraction of sludge (grey phase).

Figure 10(a) shows the actual morphology of the white phase in Figure 8(a) which is likely to be thin platelets about $2.5 \mu \mathrm{m}$ thick. The morphology of the grey sludge in Figure 8(b) is well 


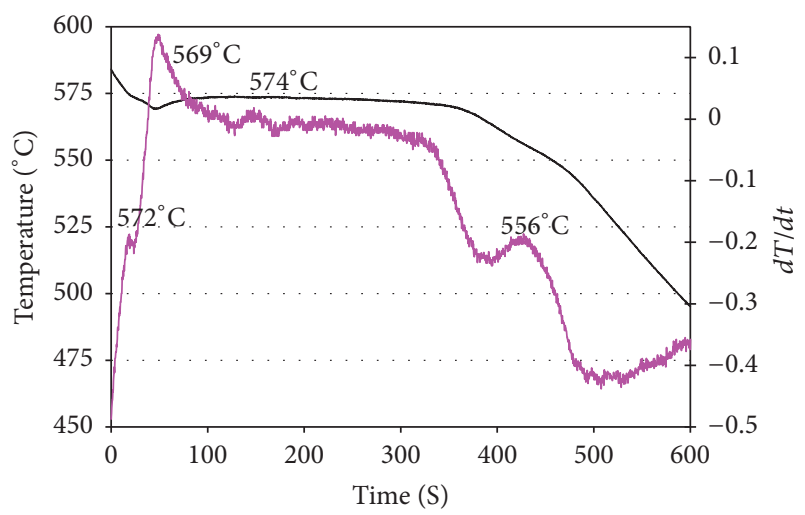

(a)

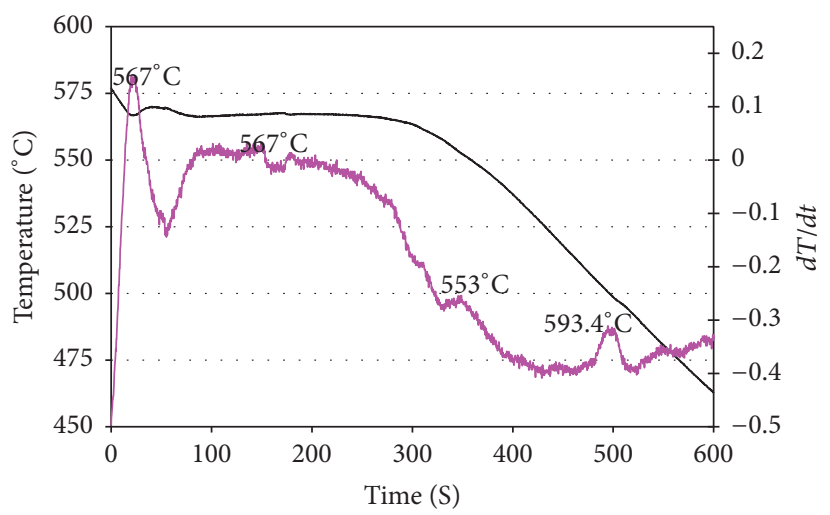

(b)

FIGURE 3: Solidification curves and their 1st derivatives obtained from (a) base alloy and (b) base alloy $+80 \mathrm{ppm} \mathrm{Sr}$.

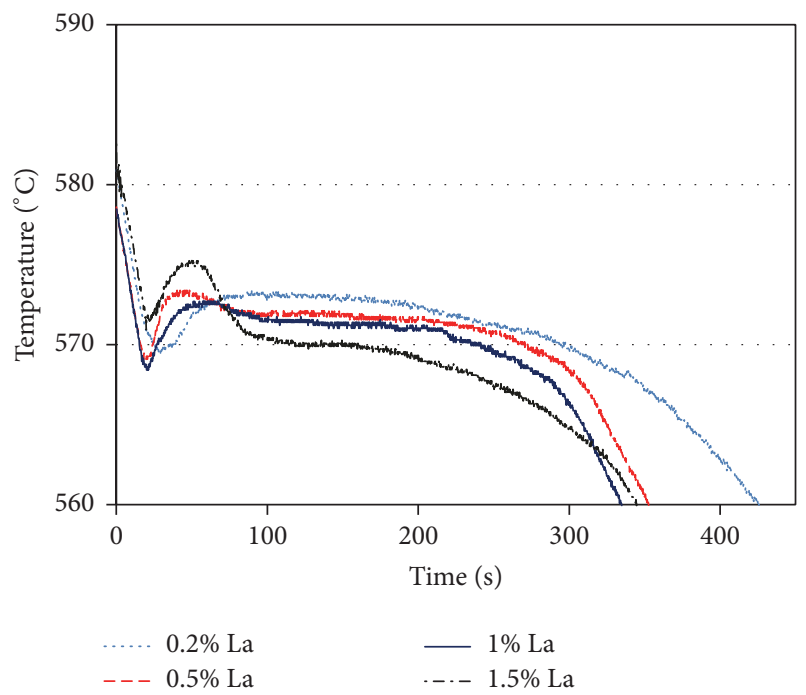

(a)

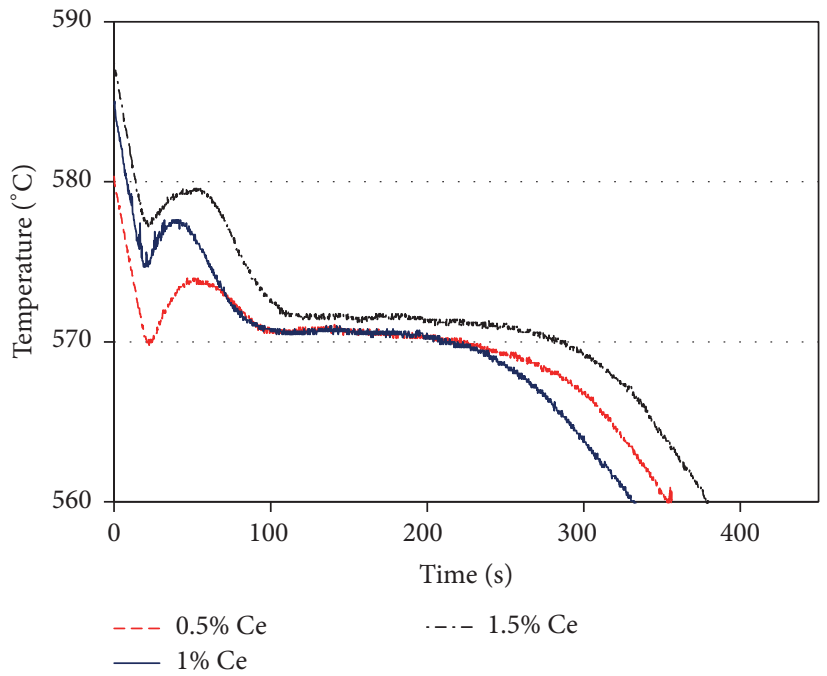

(b)

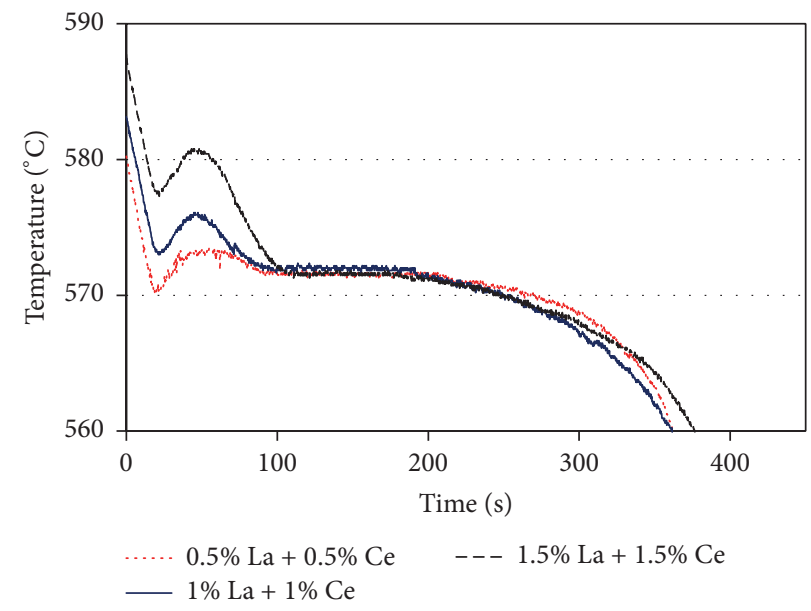

(c)

Figure 4: Temperature-time curves obtained from the base alloy with various concentrations of (a) La, (b) Ce, and (c) La + Ce. 


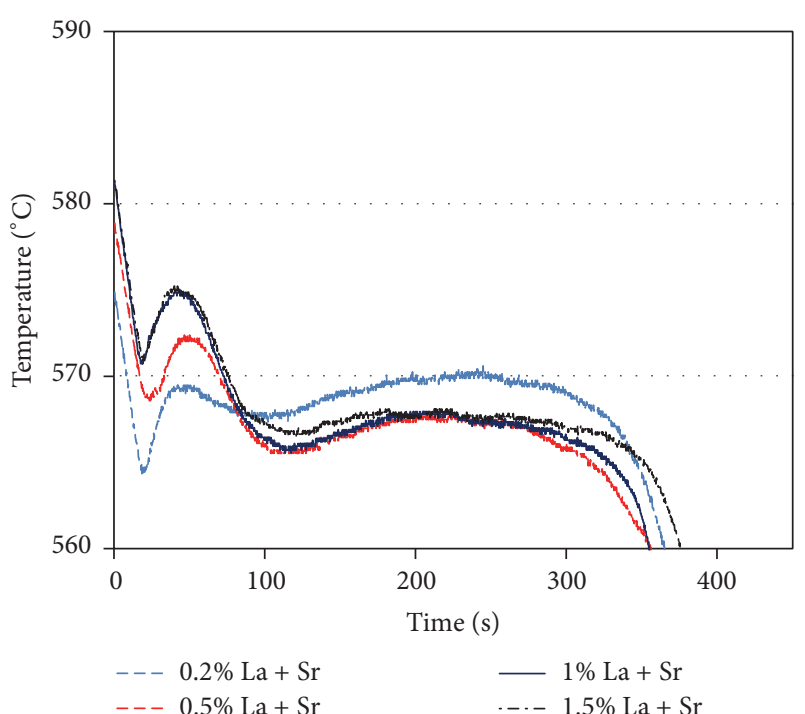

(a)

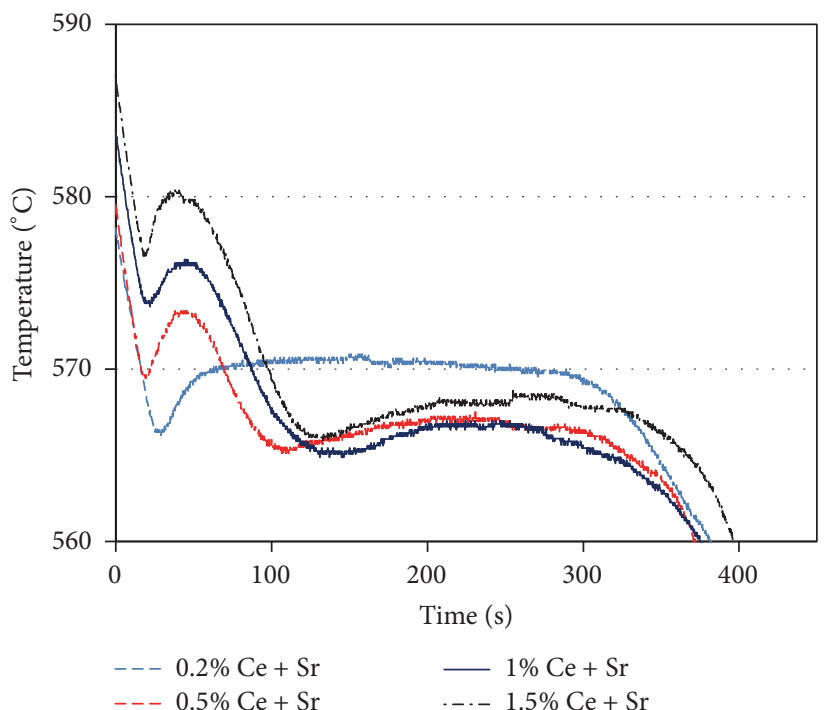

(b)

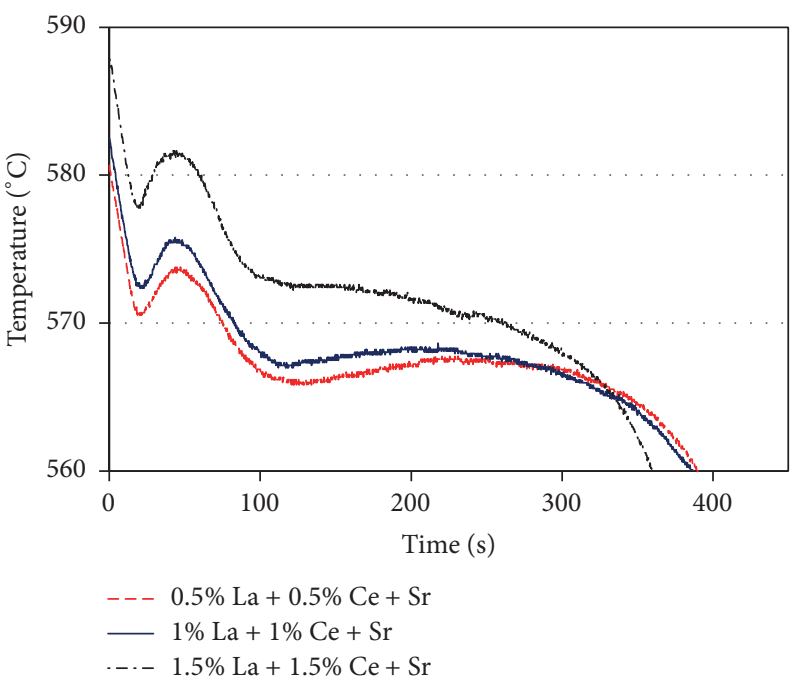

(c)

Figure 5: Temperature-time curves obtained from the modified base alloy with various concentrations of (a) La, (b) Ce, and (c) La $+\mathrm{Ce}$.

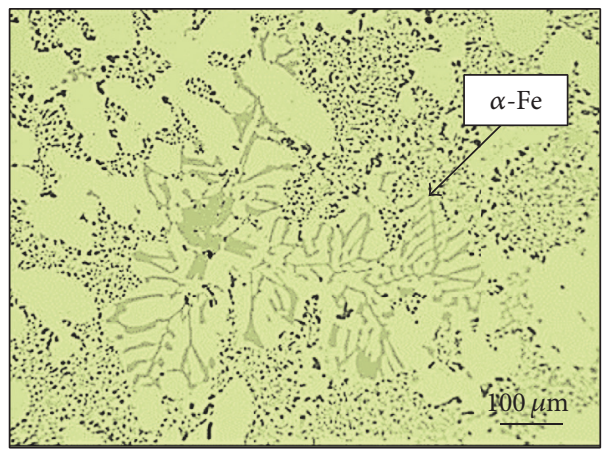

FiguRE 6: Microstructure of base alloy treated with $80 \mathrm{ppm}$ Sr. 


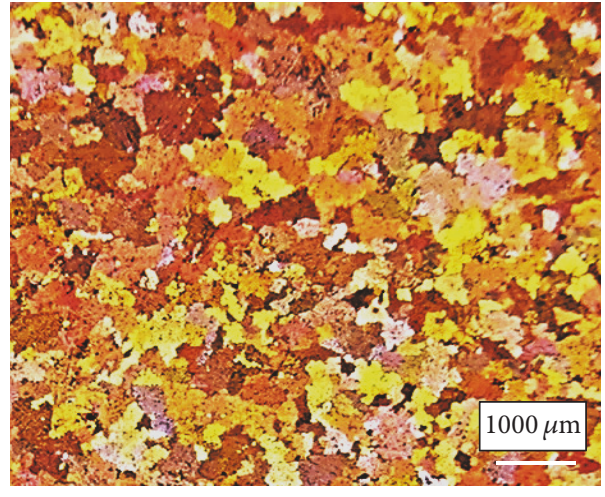

(a)

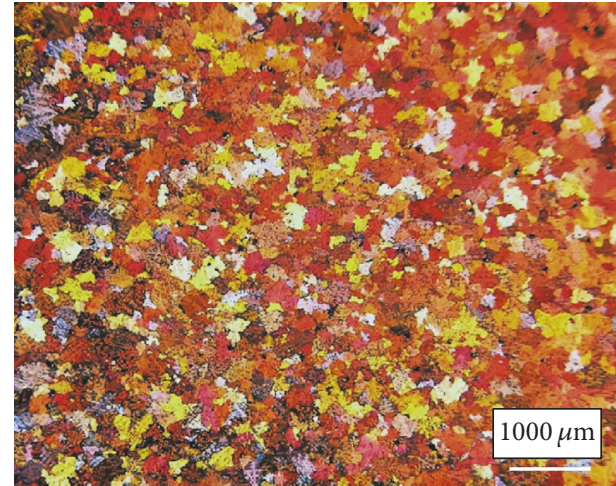

(b)

FIGURE 7: Grain size and distribution in base alloy containing (a) $0.05 \mathrm{wt} \% \mathrm{Ti}-500 \mu \mathrm{m}$ and (b) $0.15 \mathrm{wt} \% \mathrm{Ti}-200 \mu \mathrm{m}$.

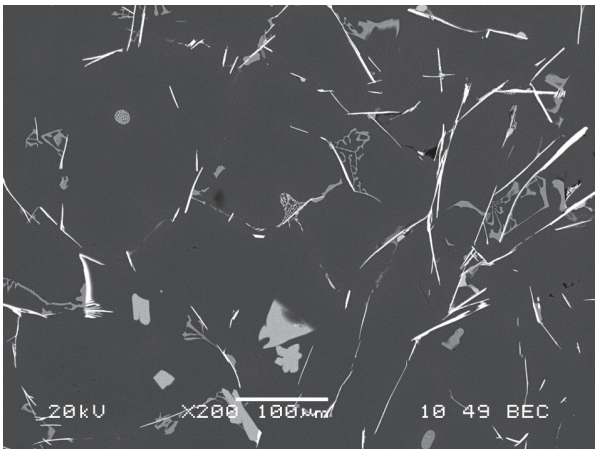

(a)

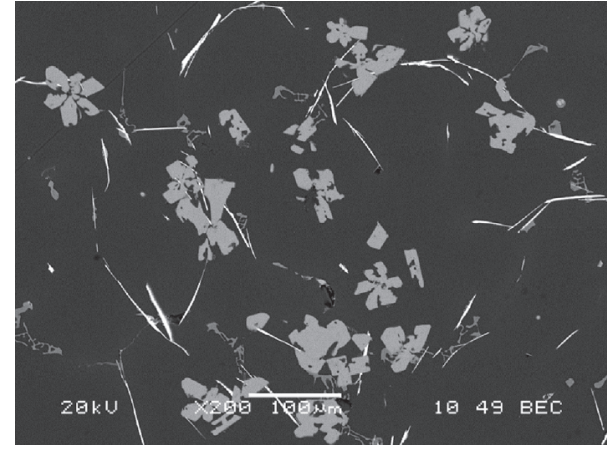

(b)

Figure 8: Backscattered electron images of base alloy $+1 \mathrm{wt} \%$ La containing (a) $0.05 \mathrm{wt} \% \mathrm{Ti}$ and (b) $0.15 \mathrm{wt} \% \mathrm{Ti}$.

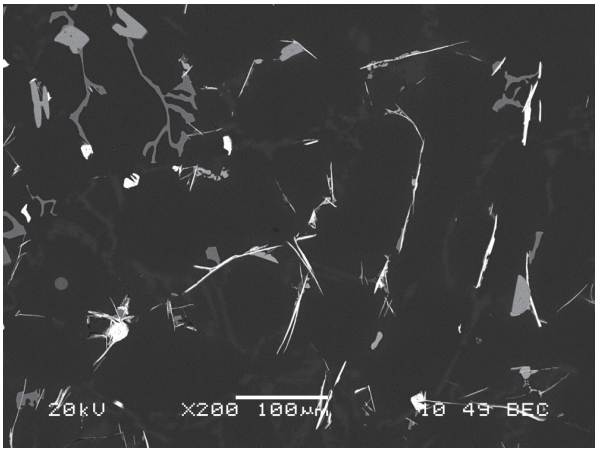

(a)

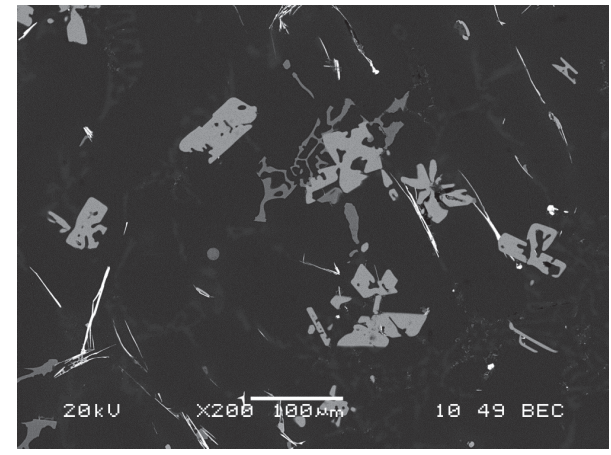

(b)

Figure 9: Backscattered electron images of base alloy $+1 \mathrm{wt} \%$ Ce containing (a) $0.05 \mathrm{wt} \% \mathrm{Ti}$ and (b) $0.15 \mathrm{wt} \% \mathrm{Ti}$.

illustrated in Figure 10(b) exhibiting the branching of the grey phase particles in different directions.

Figure 11(a) is the EDS spectrum obtained from the white phase in Figure 8(a) revealing reflections due to $\mathrm{Al}, \mathrm{La}, \mathrm{Si}$ and $\mathrm{Cu}$ with traces of $\mathrm{Fe}$. In the case of high Ti containing alloy (Figure 8(b)), the corresponding EDs spectrum (Figure $11(\mathrm{~b})$ ) reveals only three peaks caused by $\mathrm{Al}, \mathrm{La}$ and $\mathrm{Ti}$, indicating that these phases are having two distinct chemical compositions as well as precipitation temperatures. Table 3 shows the chemical composition of the two phases (at\%) and approximate chemical formula.

3.2.2. Eutectic Si Characteristics. Table 4(a) lists the variation in the size and morphology of the eutectic Si particles as a function of the added RE. It is evident that small addition of RE in the amount of $0.2 \mathrm{wt} \%$ resulted in slight 


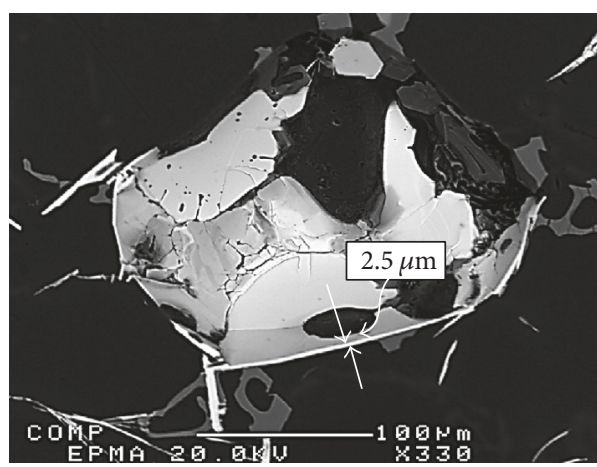

(a)

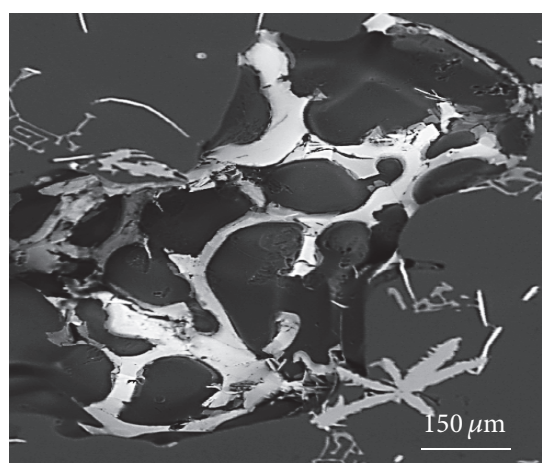

(b)

FIGURE 10: Backscattered electron images of (a) the white phase in Figure 8(a) revealing its plate-like shape, and (b) the grey sludge phase in Figure 8(b). The two straight arrows pointing towards each other in (a) simply highlight the thickness of the platelet-like phase and the curved arrow that links the label $2.5 \mu \mathrm{m}$ to the platelet indicates the actual thickness.

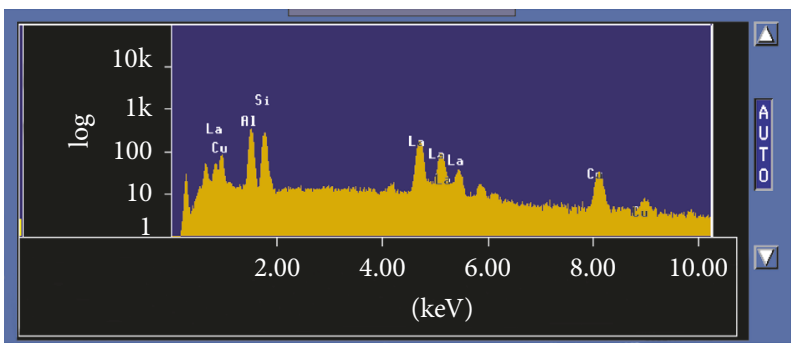

(a)

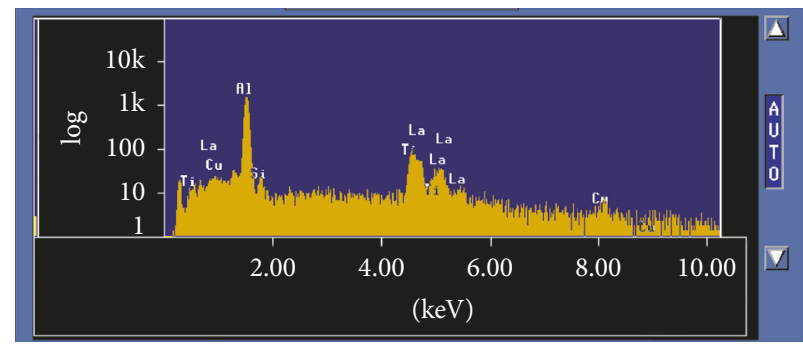

(b)

FIGURE 11: EDS spectra obtained from (a) the white phase and (b) the grey phase observed in the 1 wt\% La-containing alloy shown in Figure 8 corresponding to (a) $0.05 \mathrm{wt} \% \mathrm{Ti}$ and (b) $0.15 \mathrm{wt} \% \mathrm{Ti}$.

decrease in the average size of the Si particles (TE10 and TE11 alloys) compared to the base alloy TE. Increasing the RE concentration tended to eliminate the modification effect of $\mathrm{RE}$ leading to an increase in the eutectic Si particle size-see, TE9 alloy. The demodification effect of the RE addition is more clear in Table 4(b), due to the affinity of RE to react with $\mathrm{Sr}$ leading to $\mathrm{Si}$ particle coarsening, for example, in TE3S and TE9S alloys. It should be mentioned here that the addition of RE is associated with the decrease in the density of the eutectic Si particles especially in the Sr-modified alloys, reaching 4912 particles $/ \mathrm{mm}^{2}$ (TE9S alloy) instead of 45435 particles $/ \mathrm{mm}^{2}$ in the initial condition (TES alloy). The fact that the standard deviation is relatively high may be explained in terms of the nature of the Si particle nucleation and growth within each colony as shown in Figure 12.

The above-mentioned demodification behavior of RE is well illustrated in Figures 13 and 14. The circle in Figure 14(a) reveals the coexistence of the eutectic $\mathrm{Si}$ with the $\alpha-\mathrm{Al}_{15}(\mathrm{Fe}, \mathrm{Mn})_{3} \mathrm{Si}_{2}$ which is in contrast to what is noted in Figure 6. The solid arrow in Figure 14(c) displays partial transformation of $\beta\left(\mathrm{Al}_{5} \mathrm{FeSi}\right)$ phase into $\pi-\mathrm{Al}_{8} \mathrm{Mg}_{3} \mathrm{FeSi}$. With the increase in the concentration of RE-that is, in TE9S alloy, the open arrow in Figure 14(d) demonstrates the gradual change in the morphology of the eutectic Si particles from partially modified to a nonmodified one.

\section{Additional Points}

Summary. The results documented in the present study show that the use of the depression in the eutectic temperature as a function of alloy modification cannot be applied in the case when the alloy is treated with rare earth metals. Increasing the concentration of RE increases the solidification zone especially in Sr-modified alloys leading to poor feedability. This observation is more prominent in the case of $\mathrm{Ce}$ addition. Depending upon the amount of added Ti, two RE based intermetallics can be formed: (i) a white phase, mainly platelet-like (approximately $2.5 \mu \mathrm{m}$ thick), that is rich in RE, $\mathrm{Si}, \mathrm{Cu}$, and $\mathrm{Al}$ and (ii) a second phase in the form of grey sludge particles (star-like) branching in different directions. The grey phase is rich in Ti with some RE (almost $20 \%$ of that in the white phase) with traces of Si and $\mathrm{Cu}$. There is a strong interaction between $\mathrm{RE}$ and $\mathrm{Sr}$ which leads to reducing the efficiency of $\mathrm{Sr}$ as a eutectic Si modifier, causing particle demodification. 
TABLE 3: Chemical composition (at\%) of the white and grey phases in Figures 10 and 11.

\begin{tabular}{lcccccc}
\hline Phase & $\mathrm{Al}$ & $\mathrm{Cu}$ & $\mathrm{Si}$ & $\mathrm{Ti}$ & $\mathrm{La}$ & Suggested formula \\
\hline White & 46.47 & 9.87 & 22.37 & 00 & 21.0 & $\mathrm{Al}_{5} \mathrm{CuSi}_{2} \mathrm{La}_{2}$ \\
Grey & 85.77 & 0.43 & 0.86 & 7.76 & 4.74 & $\mathrm{Al}_{21} \mathrm{Ti}_{2} \mathrm{La}$ \\
\hline
\end{tabular}

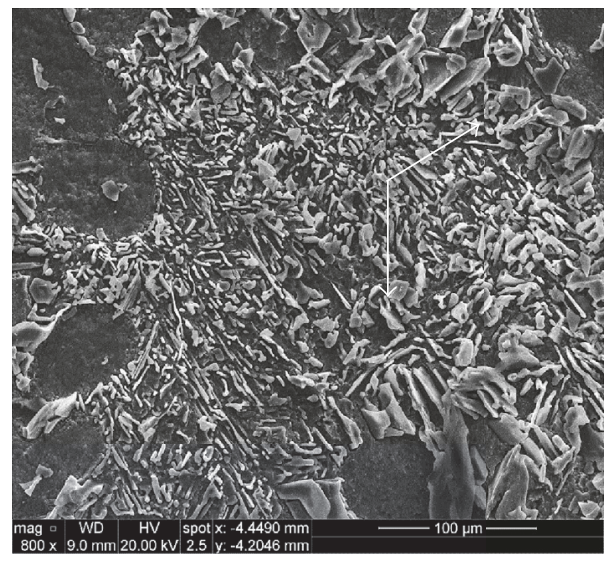

FIGURE 12: Secondary electron image showing Si particles distribution within a colony in the TES alloy. Note the difference in Si particle size in going from the centre to the periphery, white arrows.

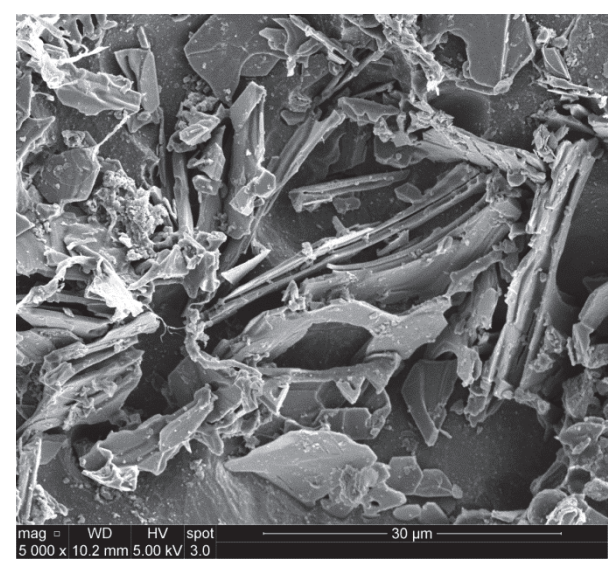

(a)

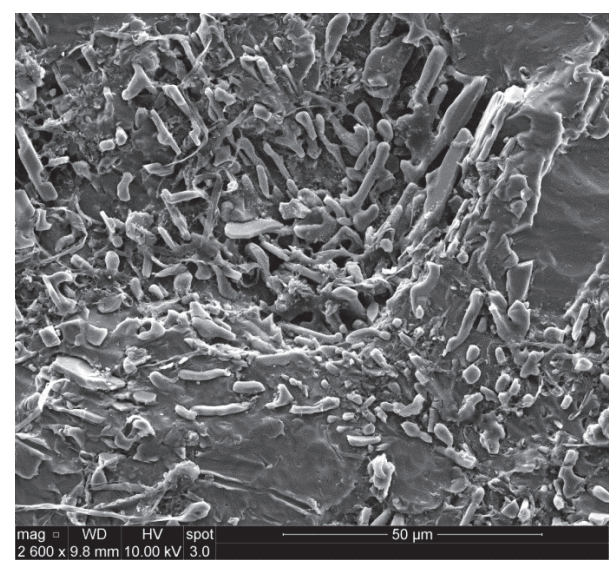

(c)

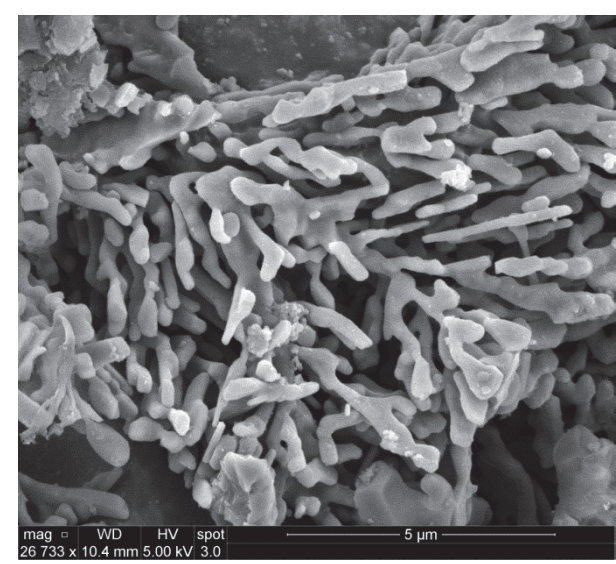

(b)

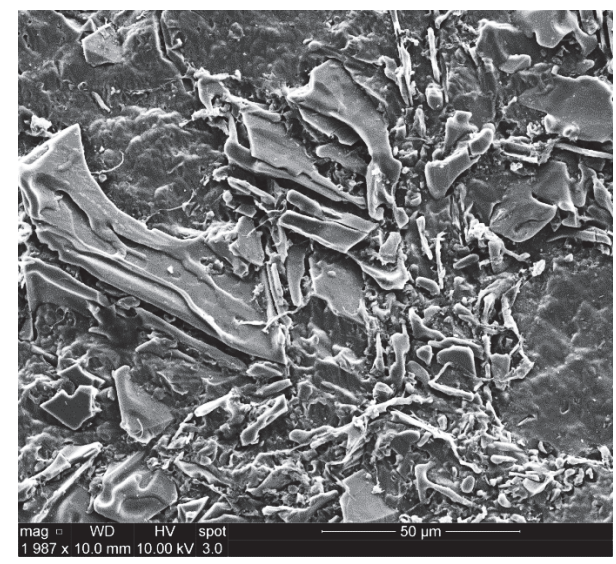

(d)

FIGURE 13: Secondary electron images of deeply etched (a) TE alloy, (b) TES alloy, (c) TE3S alloy, and (d) TE9S alloy. 

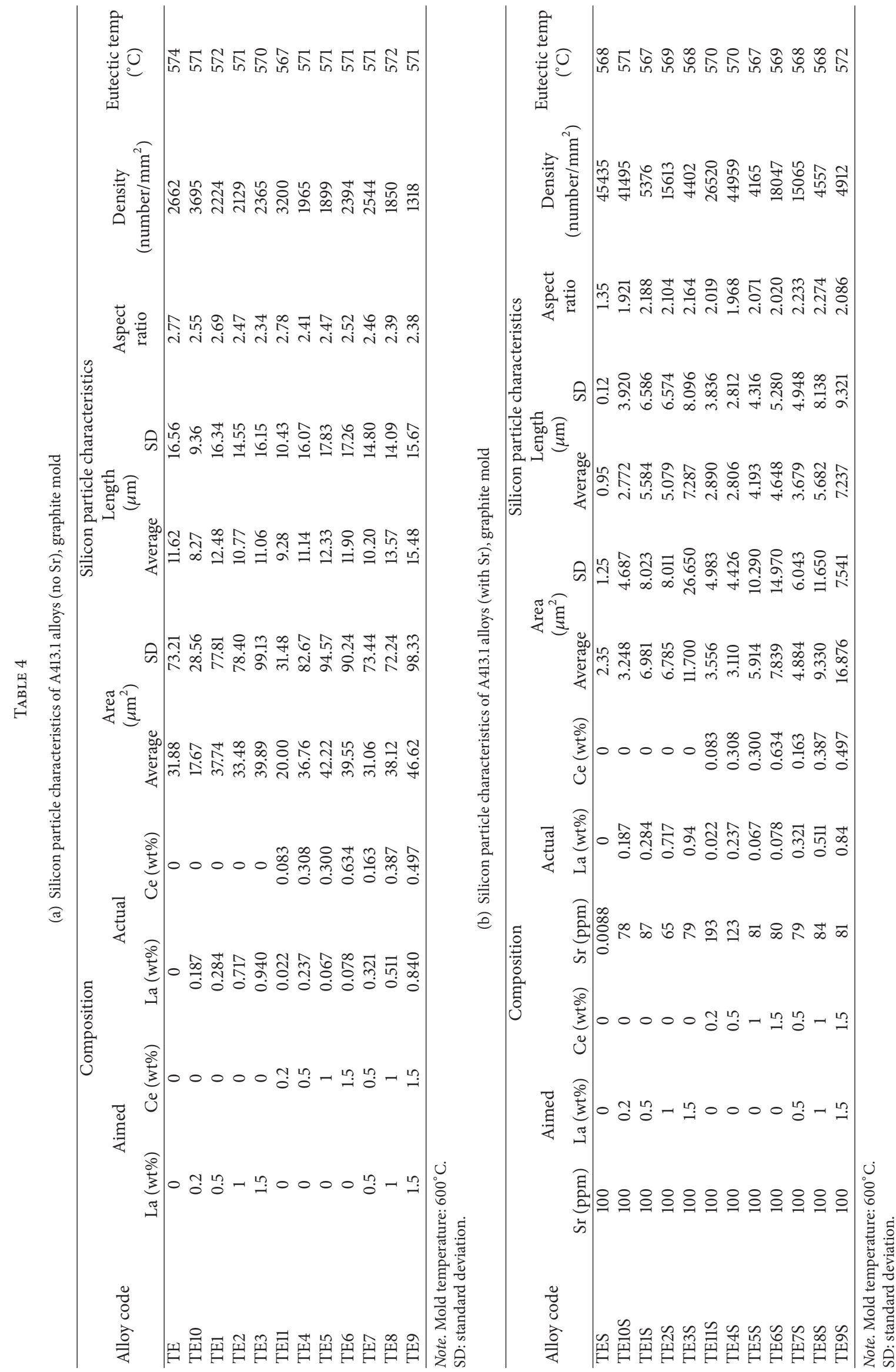


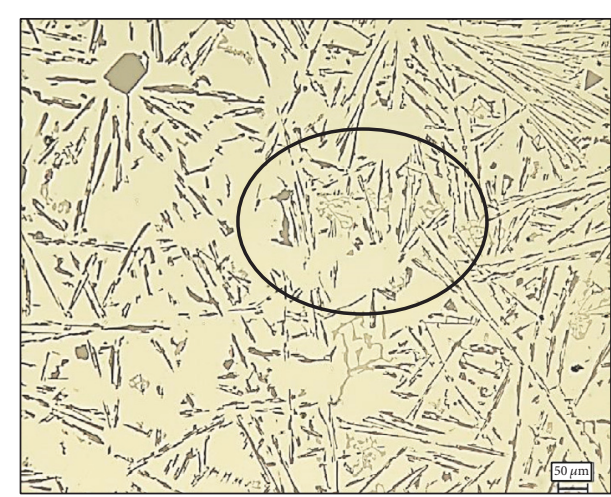

(a)

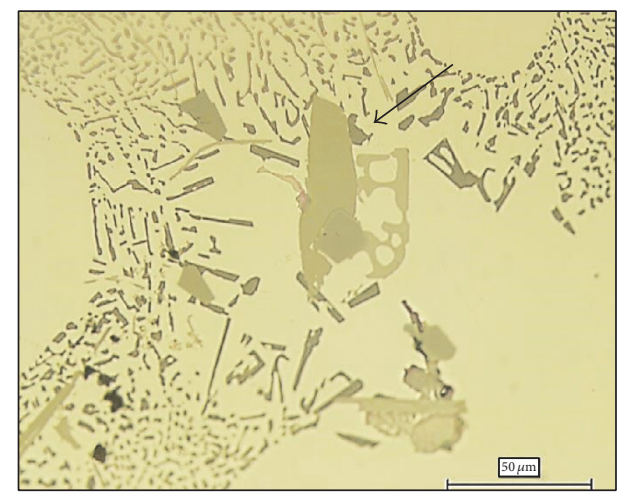

(c)

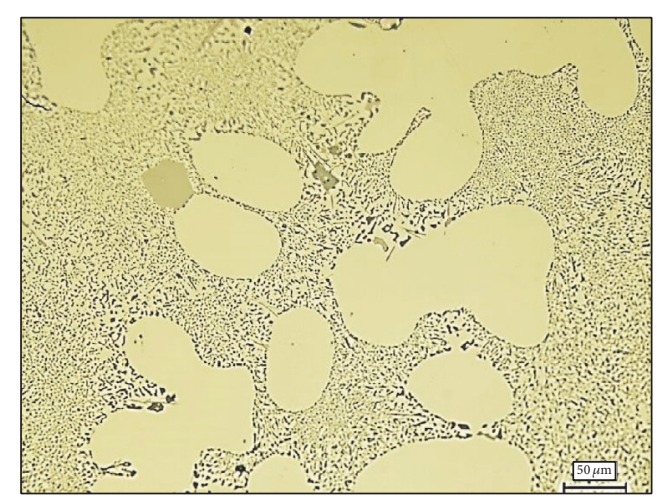

(b)

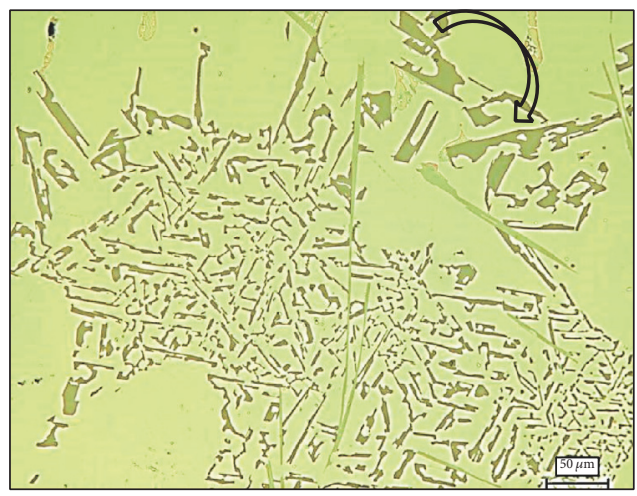

(d)

FIGURE 14: Optical micrographs of the eutectic Si particles in (a) TE alloy, (b) TES alloy, (c) TE3S alloy, and (d) TE9S alloy.

\section{Conflicts of Interest}

The authors declare that they have no conflicts of interest.

\section{Acknowledgments}

The authors would like to thank Amal Samuel for enhancing the quality of the micrographs used in the present article.

\section{References}

[1] R. Sharan and N. P. Saksena, "Rare earth additions as modifiers of aluminum silicon alloys," AFS International Cast Metals Journal, vol. 3, no. 1, pp. 29-33, 1978.

[2] S. A. Alkahtani, E. M. Elgallad, M. M. Tash, A. M. Samuel, and F. H. Samuel, "Effect of rare earth metals on the microstructure of Al-Si based alloys," Materials, vol. 9, no. 1, article 45, 2016.

[3] A. M. A. Mohamed, A. M. Samuel, F. H. Samuel, and A. M. A. Al-Ahmari, "Effects of Rare Earths on the As-Cast Microstructure of an Al-Si-Mg Alloy," in Proceedings of the 115th Metalcasting Congress, vol. 119, pp. 83-91, Transactions of the American Foundry Society, Schaumburg, Ill, USA, April 2011.

[4] A. Saoudi, F. H. Samuel, A. M. Samuel, and H. W. Doty, "Influence of the addition of rare earth metals and of overheating on microstructure and mechanical properties of aluminium alloy A319," Revue de Métallurgie, vol. 100, no. 12, pp. 1203-1212, 2003.
[5] E. M. Elgallad, H. W. Doty, S. A. Alkahtani, and F. H. Samuel, "Effects of $\mathrm{La}$ and Ce addition on the modification of Al-Si based alloys," Advances in Materials Science and Engineering, vol. 2016, Article ID 5027243, 13 pages, 2016.

[6] B. J. Ye, D. Y. Lu, and C. S. Kang, "An assessment of the role of rare earth in the eutectic modification of cast aluminum-silicon alloys," AFS Transactions, vol. 93, pp. 533-544, 1985.

[7] J. M. Kim, H. W. Kwon, and C. R. loper, "Feeding behavior of modified and unmodified Al-Si alloys," AFS Transactions, vol. 104, pp. 743-749, 1996.

[8] O. El Sebaie, A. M. Samuel, F. H. Samuel, and H. W. Doty, "The effects of mischmetal, cooling rate and heat treatment on the eutectic Si particle characteristics of A319.1, A356.2 and A413.1 Al-Si casting alloys," Materials Science and Engineering A, vol. 480, no. 1-2, pp. 342-355, 2008.

[9] O. El Sebaie, A. M. Samuel, F. H. Samuel, and H. W. Doty, "The effects of mischmetal, cooling rate and heat treatment on the hardness of A319.1, A356.2 and A413.1 Al-Si casting alloys," Materials Science and Engineering A, vol. 486, no. 1-2, pp. 241252, 2008.

[10] O. Elsebaie, F. H. Samuel, and S. Al kahtani, "Intermetallic phases observed in nonmodified and Sr modified Al-Si cast alloys containing mischmetal," International Journal of Cast Metals Research, vol. 26, no. 1, pp. 1-15, 2013.

[11] D. Apelian, S. Shivkumar, and G. Sigworth, "Fundamental aspects of heat treatment of cast Al-Si-Mg alloys," AFS Transactions, vol. 97, pp. 727-742, 1989. 
[12] M. Ravi, U. T. S. Pillai, B. C. Pai, A. D. Damodaran, and E. S. Dwarakadasa, "The effect of mischmetal addition on the structure and mechanical properties of a cast Al-7Si-0.3Mg alloy containing excess iron (up to 0.6 pct)," Metallurgical and Materials Transactions A: Physical Metallurgy and Materials Science, vol. 33, no. 2, pp. 391-400, 2002.

[13] D. Sparkman and A. Kearney, "Breakthrough in aluminium alloy thermal analysis technology for process control," AFS Transactions, vol. 102, pp. 455-460, 1994.

[14] R. Sharan and N. P. Saksena, "Rare earth modifiers of aluminum-silicon alloy," AFS International Cast Metals Journal, vol. 3, no. 1, pp. 29-33, 1978.

[15] D. Ferdian, J. Lacaze, I. Lizarralde, A. Niklas, and A. I. Fernández-Calvo, "Study of the effect of cooling rate on eutectic modification in A356 aluminium alloys," Materials Science Forum, vol. 765, pp. 130-134, 2013.

[16] R. Aparicio, G. Barrera, G. Trapaga, M. Ramirez-Argaez, and C. Gonzalez-Rivera, "Solidification kinetics of a near eutectic Al-Si alloy, unmodified and modified with Sr," Metals and Materials International, vol. 19, no. 4, pp. 707-715, 2013.

[17] L. Hengcheng, B. Juanjuan, Z. Min, D. Ke, J. Yunfeng, and C. Mingdong, "Effect of strontium and solidification rate on eutectic grain structure in an Al-13 wt\% Si alloy," China Foundry, vol. 6, no. 3, pp. 226-231, 2009.

[18] K. Nogita, S. D. McDonald, and A. K. Dahle, "Eutectic modification of Al-Si alloys with rare earth metals," Materials Transactions, vol. 45, no. 2, pp. 323-326, 2004.

[19] L. F. Mondolfo, Aluminum Alloys, Structure and Properties, London, UK, Butterworth, 1979.

[20] G. K. Sigworth, "Theoretical and practical aspects of the modification of Al-Si alloys," AFS Transactions, vol. 91, pp. 7-16, 1983.

[21] J. A. Taylor, H. Wang, D. H. St-John, and I. F. Bainbridge, "Anomalous grain coarsening behavior in grain-refined aluminum alloys cast using low superheat," in Light Metals 2001, J. Angier, Ed., pp. 935-941, TMS, Warrendale, PA, USA, 2001.

[22] D. Apelian and J. A. Cheng, "Al-Si processing variables on grain refinement and eutectic modification," AFS Transactions, vol. 94, pp. 797-808, 1986.

[23] M. Easton and D. StJohn, "Grain refinement of aluminum alloys: Part II. Confirmation of, and a mechanism for, the solute paradigm," Metallurgical and Materials Transactions A, vol. 30, no. 6, pp. 1625-1633, 1999. 

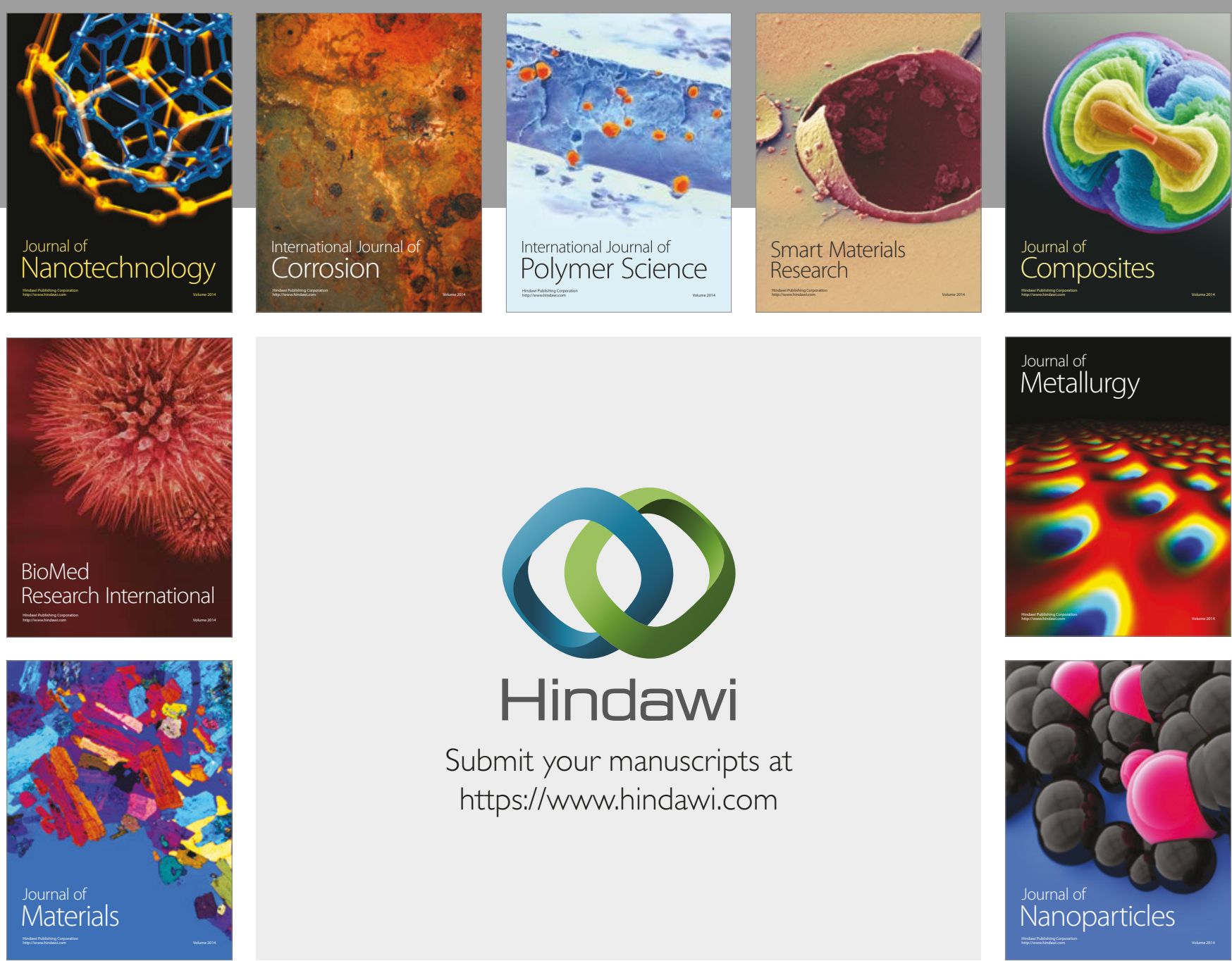

\section{Hindawi}

Submit your manuscripts at

https://www.hindawi.com
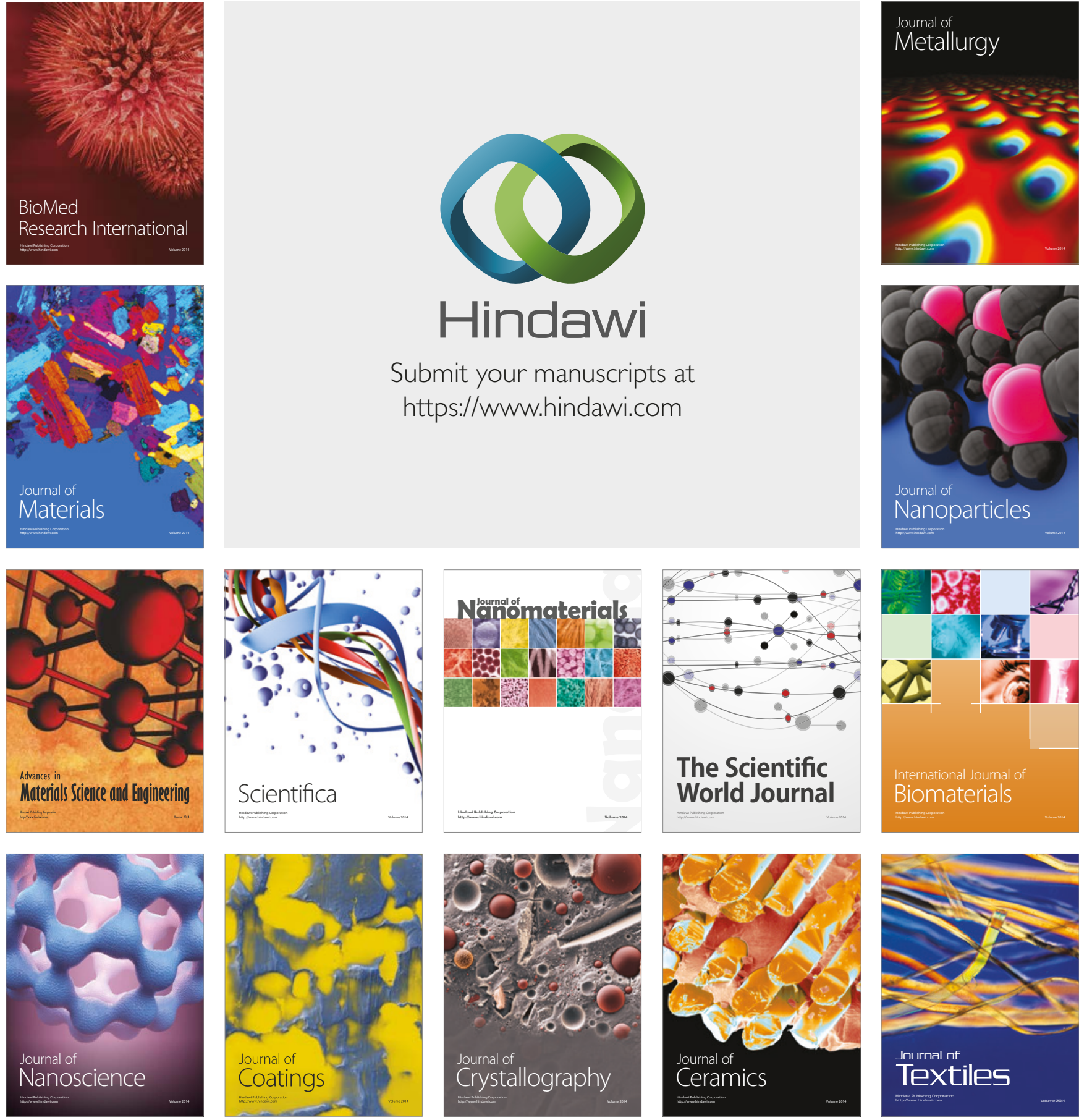

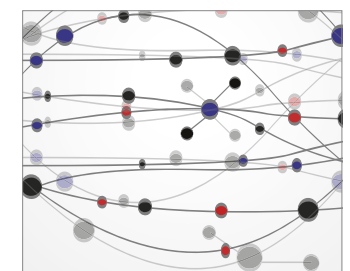

The Scientific World Journal
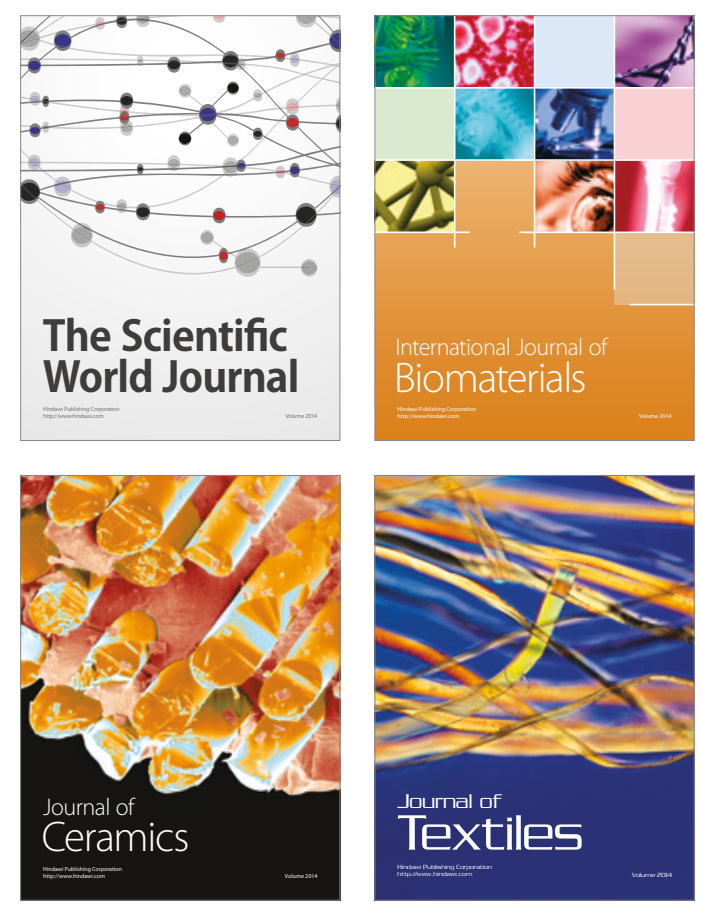